\title{
A formação Latu-senso de pesquisadores
}

A partir da experiência com a implantação do curso de especialização em saúde do trabalhador e ecologia humana, será discutida a trajetória da disciplina denominada saúde mental e trabalho, desde os seus primórdios, ainda no campo do modelo médico, até as propostas mais recentes como os estudos de psicopatologia do trabalho, considerando o estado da arte nesta matéria.

\section{Clarice Gatto}

Psicanalista e professora

do CESTEH/FIOCRUZ.
Ao refletir sobre a formação de especialistas em "saúde mental e trabalho" a partir da experiência docente - este relato traca um panorama da complexidade desta área.

Este trabalho foi inicialmente apresentado no I Seminário de Saúde Mental e Trabalho organizado pelo programa Organização do Trabalho e Saúde Mental do Instituto de Psiquiatria da Universidade Federal do Rio de Janeiro, em novembro de 1995. O tema da mesa era "formação em saúde mental do trabaIhador". Em realidade, confesso que fiquei dividida entre falar sobre os impasses que encontro na minha experiência como professora da disciplina de saúde mental e trabalho do curso de Especialização em Saúde do Trabalhador e Ecologia Humana do Centro de Estudos de Saúde do Trabalhador e Ecologia Humana (CESTEH), ou falar sobre um outro curso, aquele que eu gostaria que ele fosse!

Mas, antes de falar do "meu" sonho ou da possibilidade de "um amplo conluio entre os grupos de pesquisa", como bem disse Joāo Ferreira na apresentação daquele evento (pois certamente será necessário conluiar!) vou começar por fazer um breve balanço de nossa experiência no CESTEH, e levantar alguns impasses e as possibilidade de saídas vislumbradas.

A formação lato sensu: a especializa- çào em "saúde do trabalhador e ecologia humana"

Além do curso de especialização o CESTEH oferece outros cursos de pós-graduação, como o mestrado e doutorado em Saúde do trabalhador e em Toxicologia ocupacional e ambiental.

o curso de especialização é onde a minha experiência se concentra. É um curso de 360 horas, com 30 vagas, duração aproximada de três meses, horário integral, com uma clientela multiprofissional (médicos, psicólogos, enfermeiros, assistentes sociais, engenheiros, historiadores, dentistas e outros) e que exige como conclusāo de curso a elaboração de um trabalho, geralmente em grupo - chamado de monografia - onde os alunos apresentam publicamente suas elaboraçōes.

Este curso de especialização foi o primeiro a ser organizado, em 1986. Os objetivos eram formar profissionais de saúde inseridos nos Serviços públicos de saúde por todo o Brasil, sensíveis à articulação entre "saúde, trabalho e meio ambiente" e ampliar a reflexão sobre a qualidade da assistência clínica através do fomento de "redes de informaçōes" (sobre acidentes de trabalho, intoxicaçōes, mortalidade e morbidade) que pudessem contribuir para a reorganização dos Serviços de saúde e melhor atender à população trabalhadora.

O grupo do CESTEH também se instituiu, em meados dos anos $\mathbf{8 0}$, em torno de problemas fundamentais onde se mistura- 
vam um questionamento da posiçāo ética do pesquisador e uma crítica ao modelo médico da Medicina ocupacional que pretendia não articular os conflitos engendrados pelo processo de trabalho capitalista. Nós tínhamos entāo, de um lado, a saúde dos trabalhadores, as lutas e os movimentos (Arouca, 1978), e de outro, a ecologia humana, especialmente em sua vertente italiana (Conti, 1986) que apontava para a finitude dos recursos naturais ao aproximar criticamente uma reflexão entre capital, trabalho e meio ambiente. Ampliar a abordagem da questāo da saúde tomando como viés a saúde dos trabalhadores era, a meu ver, incluir outras reflexões, outros paradigmas, e ao abrir a escuta para novas formulações, enfrentar-se com problemas até entāo desconhecidos.

Mas, se o encontro com a novidade exercita uma certa fissura, também opera diversas negaçōes. Sejam negaçōes parcializadas, recalcadas do tipo "nāo quero saber nada sobre isso!", ou negações totais, foraclusivas (Movallali, 1988) - assim chamadas em Psicanálise - do tipo "isso nāo faz parte do campo!", em uma referência que exclui ou não assume "as formaçōes do inconsciente" los esquecimentos de palavras, os sonhos, os equívocos de linguagem e os sintomas) como acontecimentos da trajetória de constituição do corpo do sujeito e da ciência (Lacan, 1966; 1975). A negação discordancial é, no entanto, a menos encontrada: expressa através de um "nào é isso", é a forma que implica sobretudo o reconhecimento dos outros como companheiros também na diferença de olhar e de tratar os acontecimentos, pois sanciona o reconhecimento de nossa própria finitude exige, a meu ver, um deslocamento para o campo teórico de nossas divergências.

Daí, talvez, possamos pensar que as pesquisas no campo denominado genericamente de "saúde dos trabalhadores" não compõem uma demarcação imediata a partir do próprio campo. Ao incluir uma diversidade de disciplinas - este campo ampliado - possibilita a escuta das mais diferenciadas falas sobre a verdade, configurando uma singularidade no interior das pesquisas, mas também a composi-

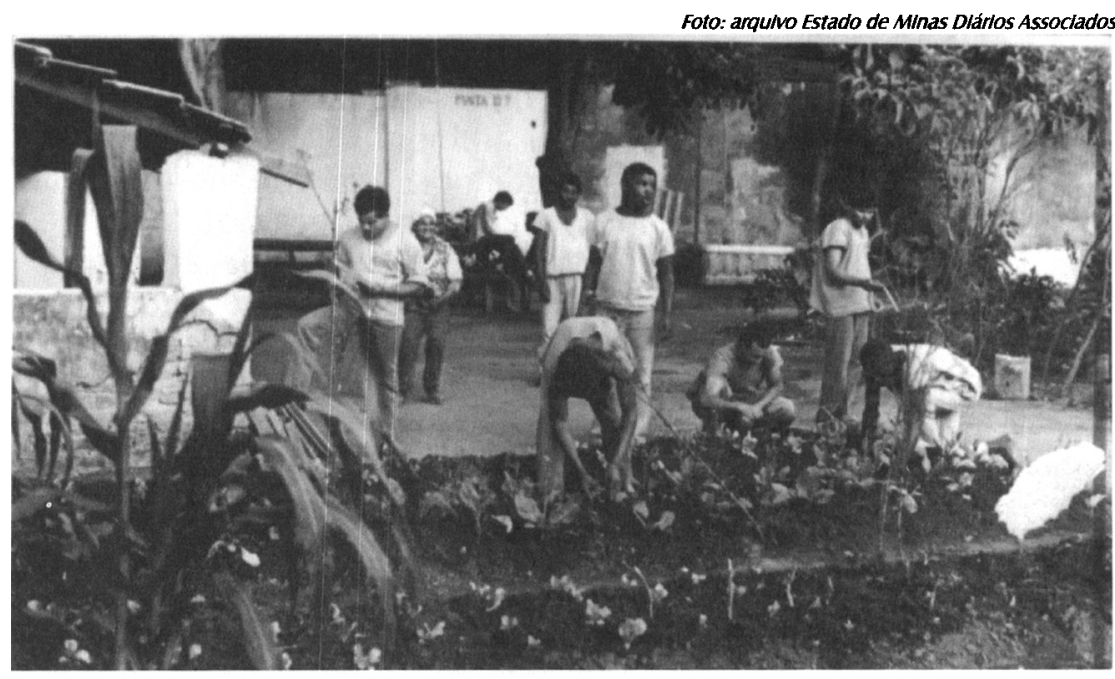

ção de um universo teórico e prático "alteritário", onde podemos ser "pares de campo" e no entanto plurais em nossas açōes. Por isso, acredito eu, é possível uma troca - simbólica, bem entendido entre as disciplinas e os temas tão diversos como os abordados pela Epidemiologia, Engenharia, Medicina, Ergonomia, Sociologia, Filosofia e a Psicanálise, por exemplo. Contudo, as conexōes na direção de uma interdisciplinaridade, no meu entendimento, comportam problemas que exigem reflexōes e demarcaçōes permanentes mais das problemáticas em questão do que do objeto a ser demarcado como alvo, se não quisermos nos perder pela estrada afora da pósmodernidade (Barbosa, 1988), ou em um emaranhado de pródigas idealizaçōes tentando achar a verdadeira verdade e deixar "a procura indefinidamente suspensa".

A especificidade histórica pela qual o próprio campo da "saúde dos trabalhadores" nestes últimos dez anos se constituiu - peculiarmente na conjuntura do CESTEH - estava ligada a uma causa que, em principio, era nossa: "a luta dos trabalhadores pela saúde." Daí a idéia, também, de um "campo" coletivo de trabalho.

Mas o que era a saúde? Era sem dúvida, como outros já apontaram (Luz, 1988), um conceito ideal, simbólico, intercambiável, e foi também de onde havíamos partido, inclusive na organização do CESTEH, mas foil também de onde se operaram as cisōes, as diferenças de 
interpretações, os impasses. E assim, noçōes como "processo de trabalho", "ecologia ambiental", "saúde e trabaIho", "toxicologia", "saúde mental e trabalho", e mesmo a noção de "clínica", de "sujeito" ou de "participaçāo dos trabalhadores", por exemplo, foram aos poucos adquirindo um amplo questionamento e demarcando as especificidades de leituras e de valores de acordo com os engajamentos teóricos, políticos, éticos e morais dos pesquisadores e sua trupe de trabalho.

Neste sentido, as abordagens em torno da Saúde mental e trabalho também sofreriam toda sorte de questionamento e de reviramento tanto dos objetos de estudo quanto das problemáticas.

\section{A trajetória da Saúde mental e traba- Iho: a problemática de uma área}

A disciplina hoje denominada Saúde mental e trabalho recebeu diversos tratamentos: iniciou-se com o módulo de Acidentes e doencas do trabalho no primeiro ano do curso. O viés era eminentemente epidemiológico, e pretendíamos analisar possiveis nexos causais entre desgaste e transtornos mentais e/ ou psíquicos. Ao se autonomizar do "modelo médico" de cunho social-epidemiológico (ou Epidemiologia crítica; Almeida, 1989; Costa, 1990) passamos a chamá-la de Saúde mental simplesmente. Na ocasião, algumas pesquisas com empresas (Metrô, Furnas) nos trouxeram a necessidade de estudarmos a "teoria do stress" no âmbito da saúde dos trabalhadores, pois a noção de stress era indiscriminadamente utilizada tanto pelos trabalhadores quanto pelos médicos e pesquisadores, sem contudo oferecer subsídios que pudessem estabelecer ligações entre o processo de trabalho e os danos mórbidos. Logo em seguida, por três anos, tornouse Psicopatologia do trabalho, especialmente após a visita em 1987 de Christophe Dejours à ENSP onde proferiu uma palestra com o tema "A intensificaçāo do trabalho". Na ocasião, lançava, com um certo atraso no Brasil (na França em 1980) seu livro A Loucura do Trabalho: Estudo de Psicopatologia do Trabalho
(Dejours, 1987). Seus trabalhos têm sido, ainda hoje, uma referência valiosa para os estudiosos na área de "Saúde mental e trabalho", especialmente, pela aproximação que pretendeu entre a psicanálise e a teoria social marxista, sublinhando a importância de um conteúdo ético na posição do pesquisador.

Em 1989, em função das lacunas na literatura brasileira - estes estudos são recentes - elaborei o projeto Loucura e trabalho, a emergência de um discurso no Brasil(1930-1945), que tinha por objetivo investigar a história no Brasil da trajetória teórica entre loucura e trabalho, tanto no domínio da Psiquiatría quanto no da Saúde pública. Nosso objetivo era operar um duplo deslocamento: primeiro, para o caso do Brasil, e segundo, para a problemática da relação entre loucura e trabalho da tese demonstrada por George Rosen e também por Michel Foucault de que teria sido fundamentalmente no ambiente de trabalho militar, em alguns países da Europa, que a preocupação com a saúde da força de trabalho ganhou materialidade e se constituiu em motivo de investigação e controle a partir da sociedade industrial. No Brasil, depois de uma longa pesquisa, identificamos nos Anais do Hospital do Exército mudanças nas abordagens teóricas porque se afastavam do modelo tradicional alienista e higienista e se aproximavam de uma proposta de articulação entre loucura e trabalho via uma leitura estratégica da psicanálise. O período de 30 a 45 correspondeu na história brasileira a um período de arrancada da industrialização e de mudanças políticas e econômicas radicais tanto na esfera institucional como nas relações de trabalho (Gatto, 1991). Observamos essas mudanças também no campo médicopsiquiátrico através da passagem de um modelo eminentemente moralizante dos anos 20 para uma medicina científica nos anos 30; e ainda que aquelas análises trouxessem a marca de um "determinismo psíquico" na articulação entre saúde mental e trabalho via psicanálise, elas se caracterizaram pela autonomia dos médicos ao realizarem os diagnósticos e ao sugerirem articulaçōes até então impensáveis. 
No início de 1990, abrimos o ambulatório para atendimento clínico aos funcionários da FIOCRUZ, como estava previsto na organizaçāo inicial do CESTEH através do FIOSAST (Serviço de atenção à saúde do trabalhadores da FIOCRUZ) e no cumprimento da Portaria 3214 do Ministério do Trabalho (1978). Descobrimos inicialmente que não sabíamos clinicar no âmbito de uma instituição pública de saúde. Era preciso, senão sustentar, pelo menos não perder tempo com as malícias e vícios que organizam burocraticamente os serviços de saúde. Era preciso escolher o que estudar. Era urgente reformular o campo da clínicae torná-lo freudiano - e incluir a experiência clínica como uma questão fundamental. E incluir essa clínica significava privilegiar a questão do sujeito - que também era trabalhador(a). A saúde coletiva - saúde dos trabalhadores - para poder operar haveria de se singularizar, estar aberta às peculiaridades das histórias de cada um, ainda que atravessadas pelo social, cultural, coletivo e econômico...

Durante dois anos a disciplina do curso de especialização se denominou $\angle o u C u$ ra e trabalho. A partir de 1994, ela foi desdobrada e ampliada, e passou de 08 horas/aula para 40 horas/aula, onde incluímos seminários anuais que passaram a tomar como eixo as conexōes entre "sujeito, linguagem e trabalho". Pretendíamos que a partir do primeiro seminário $O$ mal-estar do corpo no encontro com o trabalho realizado em 1994 (Gatto, 1997) os demais pudessem advir como questōes levantadas durante nosso tempo de trabalho no próprio seminário, fazendo valer o produto dessas reflexões coletivas. Foi a partir das indagaçōes levantadas que organizamos o segundo seminário Tempo, trabalho e movimento, em setembro de 1995.

Com os seminários - também abertos ao público interessado - pretendíamos trazer diversas leituras que pudessem contribuir para ampliar nossas reflexões, e assim nos defrontarmos com a especificidade do "campo psicanalítico" diante da complexidade, tanto teórica quanto prática, de seu exercício "por dentro" de uma institulção pública de saúde. Con- forme comentou Jacques Alain-Miller "[...] os psiquiatras nāo se preocuparam com uma sistematizaçāo, foi necessário a psicanálise colocar essa questão para que pudéssemos ver florescer seus esforços de grande síntese sobre o psiquismo". Como também é ingênuo acreditar que "a relação da psicanálise com a clínica psiquiátrica é de exterioridade, pois a descoberta de Freud está inscrita nas categorias que a psiquiatria utiliza" (Miller, 1987). O que significa dizer que a psicanálise tem muito a contribuir no âmbito da Saúde pública e coletiva no qual se insere a saúde dos trabalhadores.

O que é novo na abordagem da psicanálise, neste campo agora ampliado da "saúde dos trabalhadores", é a possibilidade também de tratamento da psicose. Pois o que observei neste percurso foi que a loucura propriamente dita, a psicose, também acaba ficando excluída das reflexões por diversos motivos e por diversos dispositivos...

A banalização, e às vezes a exclusão sumária da produção teórica da psicanálise no tratamento do que genericamente chamamos de "sofrimento psíquico" - pois foi daí que Freud partiu - corre o risco de privar o "campo" da saúde dos trabalhadores de uma aquisição fundamental de nosso século, especialmente no que concerne aos modos de existência de cada um.

Dentre as 'queixas' mais freqüentes com Freud - o que escutamos na clínica é que os seres falantes sofrem quando perdem a capacidade de trabalhar e de amar. (A fala não dá conta de dizer o que somos, ou porque evoca a polissemia de sentidos, ou pelos equívocos que cometemos ou porque ouvimos muitas vezes outra coisa... ) A psicanálise nasce, nos dizeres de Jacques Lacan, quando Freud rompe com a hipnose e funda o amor de transferência (Lacan, 1979). E por que será que ainda soa tão estranho falar de amor e ódio no âmbito da saúde? Por que será...?

Se a psicanálise vive da escuta do desejo e a ciência lou as teorias que construímos) é o que dá contorno e se sustenta de enunciar o desejo sem-saber. no entanto, uma vive de 'esclarecer' a 
outra, em um movimento onde "só-depois" (Nachträglichkeit) poderemos construir as perguntas que formulamos em nosso encontro com o real. O "discurso do analista", como pontuou Lacan (Lacan, 1975), vem ocupar um lugar na nossa cultura ao fazer laco socia/na produção de 'significantes novos' na história do sujeito ora trazendo-lhe sentido, ora mergulhando-o em uma angústia sem par. $O$ endereçamento a essa escuta é o que imprime possibilidades, penso eu, ao criar um espaço de acolhimento ao particular dos fantasmas nas produçōes desejantes para cada um. A experiência clínica da psicanálise pretendeu, com Freud, colocar em uma ordem - ao inventar o dispositivo analítico - o que anteriormente não cabia nos outros discursos (Clavreul, 1983). Onde chegará, cada um, nesta procura - ao nãosentido, ao riso, ao impossível de tudo dizer, à felicidade ou à amargura de viver, ou à simplicidade do dia-a-dia, à vontade de poder ou ao bom uso do "meu" bem! Resta uma questão a cada clínica que se inicia...

\section{O debate: a Saúde mental do traba- Iho hoje}

Existe também um debate em torno do que viria a ser 'esse campo' denominado Saúde mental "do" trabalho... Eu desdobro em três grandes eixos de pesquisas que estou propondo apenas para nos situarmos, historicamente, em nosso tempo presente no Brasil. O primeiro eixo comporta uma série de disciplinas (Epidemiologia, Psicologia social, Psicodinâmica do trabalho, Psicopatologia do trabalho, Sócio-análise, Psiquiatria, Ergonomia para citar as mais freqüentes), e toma por objeto de trabalho "os trabalhadores" e "a organizaçào do processo de trabalho" fundamentalmente. Os riscos e agravos à saúde, a noção de processo saúde-doença mental estão no horizonte dessas abordagens, e a preocupação gira em torno da "participação" dos trabalhadores nas questōes da organização do processo de trabalho; investiga-se a prevalência do "sofrimento psíquico" mais como ponto de partida, analiso eu, do que como ponto de chegada. O entendimento da tríade saber-poder-verdade em conexão com a saúde mental dos trabalhadores está na base da construção de subjetividade deste recorte teórico marcado pelo viés da Epidemiologia social e crítica (Silva, 1986).

Um outro elxo é o da prática que eu chamo de desinstitucionalista, calcado nos trabalhos de Franco Basaglia e seu "projeto de desconstrução/invenção no campo do conhecimento, das tecnociências, das ideologias e da função dos técnicos e intelectuais", como observa Paulo Amarante (Amarante, 1994). Nos últimos dez anos no Brasil, este projeto, tem sido responsável pela divulgação ampliada da discussão entre miséria, loucura e as iatrogenias das práticas em saúde mental - porque nem sempre terapêuticas - dos ambulatórios públicos de saúde mental no Brasil. Por estarem permanentemente articulando seu trabalho com a mídia, a política partidária e as reformas jurídicas de ampliaçāo de cidadania, esse grupo tem sido responsável pela re/formulação de Políticas públicas de saúde, e constantemente reabrem um debate de autocrítica que considero de extrema importância. (Pedro Gabriel G. Delgado, ao falar na Jornada de Psiquiatria sobre "Reabilitação em Saúde Mental", em setembro de 1995, colocou em reavaliação as discussōes em torno das diversas possibilidades de interpretação do dispositivo jurídico interdição e as estratégias para os "usuários" dos ambulatórios de saúde mental, por exemplo.)

Um terceiro eixo de pesquisa é o da clif nica, dos que atendem "os malucos" dos trabalhadores inseridos neste mercado global de trabalho capitalista. Aqui, tudo se torna "uma" questão e a prática "uma" singularidade... A dificuldade maior, creio eu, encontra-se mais no turbilhão de "outras" instituiçōes que gravitam em torno das reflexōes que orientam essas práticas do que propriamente no campo da clínica ambulatorial dos Serviços públicos de saúde. Aqui brincamos nos justificando que "a rede" de transferências é o que nos move. Em um debate acerca da "Psicanálise nas instituiçōes universitárias", Daniel Kuper- 
man lembrava um trabalho recente de Joel Birman chamando a atenção para uma distinção importante entre o "trabaIho de transferência" (working through) como pontuava Lacan na Direçào do tratamento (Lacan, 1966) e a "submissão transferencial"! Por não se poder fazer essa distinção "em nome" da singularidade da prática, muitas vezes se perde a autonomia mínima necessária do ato de pensar e de lançar mão de saídas particulares e criativas, fazendo a clínica sofrer de uma inibição sem par! Não nos esqueçamos que nós "psi" - ou "mentais" como costuma dizer joão Ferreira - buscamos este campo também por conta de nossas próprias neuroses, portanto é preciso tratar da nossa, ou pelo menos nos sabermos sofrendo delas para podermos ir aos poucos avançando...

Com Freud, quando interrogamos o made in Germany, o certificado de garantia é para nos certificarmos de que em realidade não há garantia nenhuma. A não ser a de que devemos poder sustentar, pelo menos, nossos atos...

Como podemos ver, "esse campo" da saúde mental e trabalho está mais próximo de uma área temática que oferece possibilidades diversas de recortes e formas de intervenção do que propriamente "um espaço de jogo, um campo de relaçōes objetivas entre indivíduos ou instituiçōes que competem por um mesmo objeto" (Bourdieu, 1974).

\section{Alguns Impasses na formação de es- pecialistas em Saúde mental e traba- Tho}

As chamadas "especializações" na Escola Nacional de Saúde Pública têm como objetivo básico reciclar ou informar profissionais de saúde, ou que trabalhem em instituiçōes afins, e que precisam se atualizar ou desenvolver pesquisas e necessitam de orientação acadêmica. Em geral, esses cursos são abertos a profissionais de várias áreas, caracterizando-se por um grupo de alunos heterogêneo. São cursos curtos (em média 360 horas/aula) e muito procurados por profissionais de todo o Brasil e por colegas da América Latina, o que o torna rico em diversidades regionais e surpreendente pelas ex- periências inovadoras, fazendo do intercâmbio um dos efeitos saborosos do curso.

A especialização em "saúde do trabalhador e ecologia humana" onde se insere a disciplina de saúde mental e trabalho também acompanha essa orientação da Escola. Porém um agravante, a meu ver, é a característica um tanto ou quanto planetária do que se supõe ser o conteúdo mínimo necessário capaz de criar a identidade ou "a cara do curso". Há também o modo como estes cursos capitalizam alunos para os cursos stricto sen$s u$, e como não poderia faltar, as razões políticas dos grupos na instituição!

Neste sentido alguns impasses que eu vejo na formação de pesquisadores para uma área de saúde mental e trabalho ficam calcados nas características do curso, no corte exagerado de diversos temas que deixam de ser abordados com mais consistência por se privilegiar cursos menores, mas com uma diversidade de informaçōes muito grande.

Nos últimos cursos, a avaliação dos alunos tem registrado a mais concreta materialidade da necessidade de organização de um curso lato sensu mais stricto sensu... em saúde mental e trabalho. Especialmente pela especificidade dos conteúdos, pela complexidade das discussōes e pela provocação que a abordagem da psicanálise faz emergir.

Para concluir, em nosso horizonte vislumbramos algumas possibilidades de desdobramentos. Uma delas é a disciplina saúde mental e trabalho se transformar em "área de concentração" dentro do curso, como tem sido tradicional na Escola Nacional de Saúde Pública, ampliando a carga horária mas mantendo a diversidade dos conteúdos. Entre os conteúdos encontramos, resumidamente, uma reflexão sobre a problemática da interdisciplinaridade dos saberes que compõem esse campo, a apresentação de algumas disciplinas (Psiçopatologia e Psicodinâmica do trabalho), alguns conceitos fundamentais da Psicanálise, visitas a empresas e mais o tema anual do seminário (também aberto ao público interessado). Porém, a reflexão sobre a experiência clínica com a psica- 
nálise dirigida a uma clientela de alunos tão diversificada e nem sempre interessada, nos remeteu à redefinição do que serla exatamente o possível neste tipo de curso. Afinal de contas, a área de saúde mental (Birman, 1992) carrega em sua história tanto a marca do "modelo asilar" quanto as referências conceituais do modelo médico-psiquiátrico que intervêm no corpo do sujeito via processo saúde-doença, e se utilizam de formas de tratamento e encaminhamentos que além de supor um saber a priori demandado à figura do médico também exige que este possa saber responder ao que lhe foi solicitado. Posicão ambiguamente pedida ao psicanalista, mas os sintomas sobre os quais a psicanálise se debruça, por exemplo, em realidade constituem um locus a posteriori. Uma outra possibilidade vislumbrada tomaria por viés a clínica e a subjetividade em suas vicissitudes tais como as

\section{Referências Bibliográficas}

aborda a psicanálise de Freud, especialmente no convite que nos faz Jacques Lacan de retorno aos textos originais e de encontro com as dificuldades que estes nos trazem ao precisarmos por ventura traduzi-los ou vertê-los. Este curso se caracterizaria, neste sentido, pela noção de Extensão ao invés da de Especialização. Nesta perspectiva poderemos abrilo para outros profissionais de outras áreas - além de psicólogos e médicos - e assim ampliarmos nosso encontro com áreas que há algum tempo se interessam pelos temas e formulaçōes tanto da psicanálise quanto da saúde e do trabalho. tais como demonstram alguns estudos de filosofia, antropologia, cinema, literatura, teatro, lingüistica, e as artes plásticas, por exemplo. Enfim, a idéia está lançada e é sobretudo para sair do "modelo manicomial", aquele imortalizado por Machado de Assis em $O$ alienista.
Almeida Filho, N. de. (1989). Epidemiologia sem Números. Rio de Janeiro: Campus.

Amarante, P. (1995). O homem e a serpente: outras histórias para a loucura e a Psiquiatria. Tese de doutorado: Escola Nacional de Saúde Pública da FIOCRUZ, Rio de Janeiro.

Arouca, A.T. (1978) Análise dos determinantes das condiçōes de saúde da população brasileira. Em Guimarães, R. (org.), Saúde e medicina no Brasil. 2ed. Rio de Janeiro: Graal.

Assis, M. de. O alienista e outros contos. Em Obras Completas. São Paulo: Cúrculo do Livro.

Bourdieu, P. (1974). Alta costura e alta cultura, mimeo.

Birman, J. (1992). A cidadania tresloucada. Em Amarante, P. \& Bezerra, B. Jr. (org.) Psiquiatnia sem Hospício. Rlo de Janelro: Relume-Dumará

Clavreul, J. (1983). Ordem médica: poder e impotência do discurso médico. São Paulo: Brasiliense.

Conti, L. (1986). Ecologia. Capital, trabalho e ambiente. São Paulo: Hucitec.

Costa, D.C. (org.). (1990). Em Epidemiologia, Teorla e Objeto. São Paulo: Hucitec-Abrasco.

Dejours, C. (1987). A toucura do trabalho. Estudos de Psicopatologla do trabalho. Sāo Paulo: Oboré.

Freud, S. (1973) Omalestar da cultura. Em Obras Com pletas. Volume III. Madri: Nueva.
Gatto, C. et al. (1989) Stress e traba/ho, análise da litera tura na América latina. Relatório de pesquisa desenvor vido no Centro de Estudos de Saúde do Trabalhador e Ecologla Humana da FIOCRUZ, com apoio CNPq., Rio de Janeiro, mimeo.

Gatto, C (1991). Loucura e trabalho: a emergência de um discurso no Brasil (1930-1945). Projeto de tese de mestrado apresentado ao Instítuto de Medicina Social da UERJ, RJo de Janeiro, mimeo.

Gatto, C. (org.). (1966). O malestar do corpo no encontro com o trabalho. Rio de Janeiro, 1997, no prelo. Lacan, J. (1966). Ecrits. Paris: Seuil. . (1975). Encore. Le séminaire le live XX. Parls: Seuil.

(1979). Os quatro conceitosfundamen tais da psicanálise. O seminário livo 11. Ro de Janeiro: Zahar.

Luz, M.T. (1988). Natural, racional, social: razão médica eradonalidade científica modema. Rio de Janeiro: Campus.

Miller, J.A. (1987). A Psicanálise e a Psiquiatria. Em Falo. Número 1. Salvador: Fator.

Movallali, K. (1988). Questionner la dénégation. Em Littoral. Número 25. Paris: Erès.

Silva, E.S. (1986). Crise Econômica, Trabalho e Saúde Mental. Em Silva, E. S et al. Crise, Traba/ho e Saúde Mental no Brasil. São Paulo: Traço. 